MATEC Web of Conferences 33, 04005 (2015)

DOI: $10.1051 /$ matec conf/20153304005

(C) Owned by the authors, published by EDP Sciences, 2015

\title{
Effects of B2 nanoprecipitates on the phase stability and pseudoelastic behavior of Fe-Mn-Al-Ni shape memory alloys
}

\author{
P. La Roca ${ }^{1,2}$, J. Medina ${ }^{3}$, C.E. Sobrero ${ }^{4}$, M. Avalos ${ }^{4}$, J.A. Malarria ${ }^{4}$, A. Baruj ${ }^{1,2}$, M. Sade ${ }^{1,2, a}$ \\ ${ }^{1}$ Centro Atómico Bariloche - CNEA and Instituto Balseiro (UNCuyo), 8400 S. C. de Bariloche, Río Negro, Argentina \\ ${ }^{2}$ Consejo Nacional de Investigaciones Científicas y Técnicas (CONICET), Argentina \\ ${ }^{3}$ Universidad Nacional del Nordeste, Corrientes, Argentina \\ ${ }^{4}$ Instituto de Física Rosario - CONICET-UNR, Rosario, Argentina
}

\begin{abstract}
Samples of a Fe- $\mathrm{Mn}_{36}-\mathrm{Al}_{15}-\mathrm{Ni}_{7.5}$ shape memory alloy were subjected to different thermal treatments at $200^{\circ} \mathrm{C}$ (namely for $0 \mathrm{~min}, 10 \mathrm{~min}, 20 \mathrm{~min}$ and $3 \mathrm{~h}$ ) in order to evaluate the evolution of the coherent precipitates related to the pseudoelastic behavior. After performing the thermal treatments, samples were studied by means of electrical resistivity in experiments aimed at evaluating the effect of precipitation on the martensitic transformation temperatures and at determining the possible effects of thermal cycling. Mechanical tests were performed to measure the degree of pseudoelastic recovery for each thermally treated sample. Evidences of pseudoelastic behavior were found even in samples subjected to a rather short treatment such as 20 min after three thermal cycles. Transmission electron microscopy (TEM) observations were performed in order to identify the distribution and size of B2 nanoprecipitates after the various thermal treatments.
\end{abstract}

\section{Introduction}

Shape memory effect and pseudoelasticity are well known properties of technological interest which are present individually or simultaneously in several alloy systems. The origin of each phenomenon lies in the type of martensitic transition taking place in the material.

It has recently been found that Fe-Mn-Al-Ni alloys show an excellent pseudoelastic effect [1]. The ternary alloy $\mathrm{Fe}_{49} \mathrm{Mn}_{36} \mathrm{Al}_{15}$ (at.\%) shows a rather unusual martensitic transformation between an austenitic bcc phase $(\alpha)$ retained by quenching from high temperatures and a martensitic fcc structure $\left(\gamma^{\prime}\right)$ [2]. This transition is nonthermoelastic and takes place at a temperature close to room temperature. The addition of $\mathrm{Ni}$ and the precipitation in the matrix of a bcc structure with a B2 order lead to a thermoelastic transition in this Fe-Mn based alloy. This has been shown in the $\mathrm{Fe}_{43.5} \mathrm{Mn}_{34} \mathrm{Al}_{15} \mathrm{Ni}_{7.5}$ (at.\%) alloy with nanometric $\mathrm{NiAl}$ precipitates where martensitic plates grow during cooling and interfaces go back when heating takes place [1].

\footnotetext{
a Corresponding author: sade@cab.cnea.gov.ar
}

In Fe-Mn alloys with composition up to 15 at.\% $\mathrm{Mn}$, the fcc $(\gamma)$ phase transforms into $\alpha^{\prime}$ (martensitic bcc). Similarly to what is found in the ferrite phase of standard steels, the $\alpha$ phase in this system has a ferromagnetic order transition at Curie temperature $\mathrm{T}_{\mathrm{c}}$. This magnetic ordering stabilizes the $\alpha^{\prime}$ phase, leading to a large difference between the martensitic transformation and retransformation temperatures. For larger amounts of $\mathrm{Mn}$, and $\mathrm{Al}$ contents higher than 15 at. $\%, \mathrm{~T}_{\mathrm{c}}$ decreases down to temperatures close to the ambient one and a difussionless transition $\alpha-\gamma^{\prime}$ has been reported [2]. It is remarkable that the volume change associated to this transition is small, which is a usual requirement to have a thermoelastic martensitic transition. The martensitic transition in $\mathrm{Fe}-\mathrm{Mn}-\mathrm{Al}$ alloys takes place at temperatures smaller than $T_{c}$, while the $\gamma^{\prime}$ martensite exhibits an antiferromagnetic ordering with a Néel temperature $\left(\mathrm{T}_{\mathrm{N}}\right)$ close to $40^{\circ} \mathrm{C}[1]$.

Studies of the Fe-Mn-Al system phase diagram have followed both experimental and thermodynamic 
approaches [3]. This knowledge enabled to evaluate the composition and temperature range where the involved phases are stable. Additionally, the effect of magnetic interactions on the stability could also be evaluated. In the Fe-Mn-Al-Ni system where pseudoelasticity has been found, the Ni amount is small and, according to several authors, this element mainly forms NiAl precipitates with a B2 structure. It would then be possible to use the available information about the ternary Fe-Mn-Al system as a first step to understand the behavior of the quaternary alloy.

Two interesting properties characterize the Fe-Mn-Al$\mathrm{Ni}$ pseudoelastic alloys and make them attractive for potential applications: a large hysteresis in polycrystalline material, which is extremely convenient for applications used to dissipate energy, and a small effect of temperature changes on the critical stress to induce the martensite. This slight effect of temperature is probably related to the small entropy change between the involved structures.

Another interesting technological aspect concerning $\mathrm{Fe}-\mathrm{Mn}-\mathrm{Al}-\mathrm{Ni}$ alloys is related to the changes in magnetic properties occurring during the martensitic transition. As an example, it has been shown that in $\mathrm{Fe}_{43.5} \mathrm{Mn}_{34} \mathrm{Al}_{15} \mathrm{Ni}_{7.5}$ melt spun ribbons, the magnetic permeability strongly changes (by approximately $12 \%$ ) when the martensite is stress induced, even if deformations as small as $0.5 \%$ are imposed [4]. Considering this result, a possible application for these alloys would be in contactless strain sensors.

The relationship between microstructure and functional properties of shape memory alloys has long been a focus of interest. Recent findings have shown that the reversibility of certain martensitic transitions can be strongly favored if the grain size $d$ increases reaching values higher than the specimen size $D$ in the so-called "bamboo microstructures". For example, this is the case for $\mathrm{Cu}$ based polycrystalline alloys where pseudoelasticity and shape memory effect are enhanced if $d / D>1$ [5-9]. This interesting effect has also been reported for Fe-Mn-Al-Ni alloys, where better pseudoelastic properties are obtained for bamboo microstructure $[1,10]$. It is also known that the grain size affects the martensitic transformation temperatures. In particular, a sufficiently large decrease of the grain size, may stabilize the austenite leading to a strong decrease in the martensitic transformation temperatures [9,11-13].

An additional relevant microstructural feature of Fe$\mathrm{Mn}-\mathrm{Al}-\mathrm{Ni}$ alloys is the presence of coherent precipitates in the matrix. In Fe-Mn shape memory alloys it has been found that the shape memory effect is improved if precipitates are introduced [14]. It has been also shown that the presence of precipitates in addition to a small grain size and a selected crystallographic texture lead to good pseudoelastic properties in Fe-Mn-Ni alloys [15]. In Fe-Mn-Al-Ni alloys, nanoprecipitates seem to play a significant role on the thermoelastic behavior and the related pseudoelasticity $[1,16]$. Although it has been reported that nanoprecipitates are observed after $3 \mathrm{~h}$ at $200^{\circ} \mathrm{C}$, a deeper understanding is still required in the way in which they are formed and the specific role they play on the relative stability of phases and the pseudoelastic effect. Additionally, precipitates might have some effect on the crystallographic distortion present in the martensite which is related with the formation of nanotwins [16]. This work it is aimed at analyzing the evolution of precipitates in Fe-Mn-Al-Ni alloys after thermal treatments at $200^{\circ} \mathrm{C}$ to improve the understanding of their effects on the relative phase stability and the pseudoelastic effect.

\section{Experimental procedures}

A $\mathrm{Fe}_{43.5} \mathrm{Mn}_{34} \mathrm{Al}_{15} \mathrm{Ni}_{7.5}$ alloy (15 g) was arc melted under Ar atmosphere and encapsulated in a quartz tube under a similar atmosphere. The alloy was thermally treated at $1000^{\circ} \mathrm{C}$ for $48 \mathrm{~h}$ and water quenched breaking the capsule. The alloy was then hot-rolled at $1000^{\circ} \mathrm{C}$ leading to a slab with a thickness of $1.5 \mathrm{~mm}$. Samples of different shapes were then obtained from the slab according to the type of measurement to be performed. Each specimen was thermally treated for $30 \mathrm{~min}$ at $1200^{\circ} \mathrm{C}$ and water quenched in order to retain the $\alpha$ structure. Thermal treatments were then performed by keeping the samples at $200^{\circ} \mathrm{C}$ for different time intervals in order to evaluate changes in the relative phase stability, pseudoelastic properties and microstructure. Table 1 shows nomenclature used for samples and the corresponding thermal treatments.

Table 1. Samples and thermal treatments

\begin{tabular}{|c|c|}
\hline Sample & $\begin{array}{c}\text { Thermal } \\
\text { Treatment }\end{array}$ \\
\hline $\mathrm{AC}$ & As-cast \\
\hline $\mathrm{T} 10$ & $200^{\circ} \mathrm{C} \times 10 \mathrm{~min}$ \\
\hline $\mathrm{T} 20$ & $200^{\circ} \mathrm{C} \times 20 \mathrm{~min}$ \\
\hline $\mathrm{T} 3 \mathrm{~h}$ & $200^{\circ} \mathrm{C} \times 3 \mathrm{~h}$ \\
\hline
\end{tabular}

Electrical resistivity measurements as a function of temperature were performed in order to determine the critical transformation temperatures for the different samples. Additionally, each sample was thermally cycled 3 times in order to have an initial evaluation of the effect of cycling on the phase transformations for this material.

The microstructure was analyzed by the SEM-EBSD technique in the austenitic structure. As the specimens only differ in the time interval of the thermal treatment performed at $200^{\circ} \mathrm{C}$ it can be considered that the $\mathrm{d} / \mathrm{D}$ ratio is the same for all the samples. Rectangular specimens $(30 \mathrm{~mm} \times 1 \mathrm{~mm} \times 0.5 \mathrm{~mm})$ initially with the $\alpha$ structure were tensile tested with an Instron 5567 mechanical testing machine in order to evaluate the pseudoelastic properties of the material. Tests were performed at $20^{\circ} \mathrm{C}$ using special grips designed for thin specimens. Deformations were measured by using an Instron extensometer. In this way it was possible to determine the amount of pseudoelastic reversibility by measuring deformations smaller than $1 \%$. 
The analysis of the precipitates was performed by transmission electron microscopy (TEM), using a Philips CM200 microscope equipped with an Ultra Twin objective lens. Samples were prepared by mechanical polishing and double jet electropolishing using a Tenupol 5 device. A solution of $5 \%$ percloric acid in acetic acid was used at $10^{\circ} \mathrm{C}$, applying $40 \mathrm{~V}$.

\section{Results}

Fig. 1 shows the electrical resistivity measurements as a function of temperature for all specimens listed in Table 1. Although the martensitic transformations can be detected in these measurements due to the presence of hysteresis, it is difficult to identify the transformation temperatures. Information about the magnetic transitions is somehow easier to obtain since both the antiferromagnetic ordering of the $\gamma^{\prime}$ martensite and the ferromagnetic ordering corresponding to the $\alpha$ austenite lead to minima in the electrical resistivity curves. Fig. 1a shows the results corresponding to the As-cast sample (labeled AC) and the material treated at $200^{\circ} \mathrm{C}$ for $3 \mathrm{~h}$ (T3h).

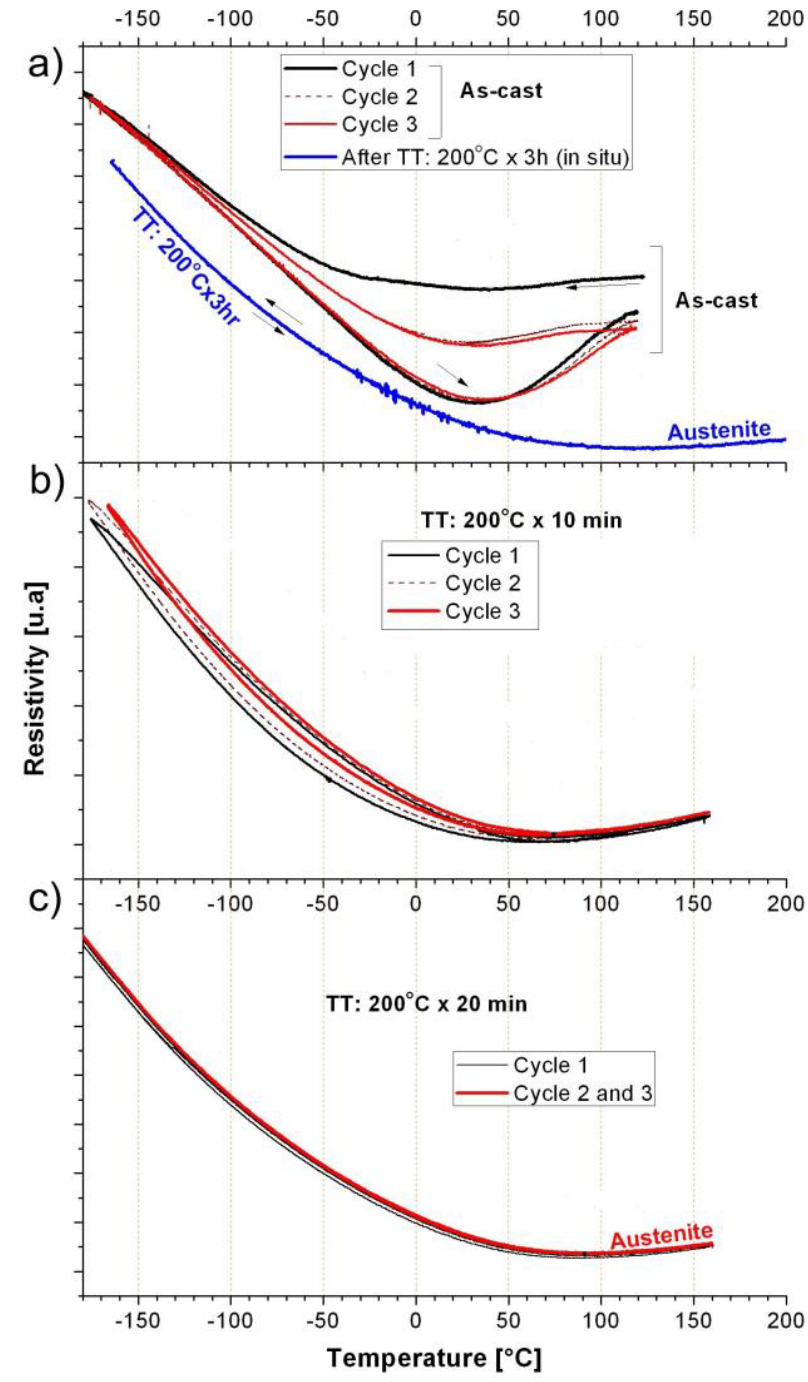

Figure 1. Electrical resistivity as a function of temperature for samples subjected to different thermal treatments at $200^{\circ} \mathrm{C}$. In each case, the first 3 thermal cycles are shown. a) $\mathrm{AC}$ and $\mathrm{T} 3 \mathrm{~h}$ samples (blue). b) T10 sample. c) T20 sample.

The electric resistive behavior of these materials is quite different. The AC sample shows significant hysteresis in its first cycle indicating the presence of the martensitic transition. The following 2 cycles present a decrease in the resistive hysteresis indicating a reduction on the amount of thermally induced martensite. This reduction could be associated to a decrease of the $\alpha \rightarrow \gamma^{\prime}$ martensitic transformation temperature $\left(\mathrm{M}_{\mathrm{s}}\right)$. The T3h sample does not display hysteresis, indicating that its thermal treatment suppressed the martensitic transformation. This result coincides with that reported in the literature for samples displaying good pseudoelastic properties $[1,10]$. Figs. $1 \mathrm{~b}$ and $1 \mathrm{c}$ show the resistivity results for the $\mathrm{T} 10$ and $\mathrm{T} 20$ samples, respectively. Compared to the AC sample, the resistive hysteresis in the first cycle is small in both cases indicating a limited amount of martensitic transformation. As in the case of the AC sample, the resistive hysteresis decreases in the subsequent cycles. In particular, 2 cycles were enough to suppress the martensitic transformation in the T20 material.

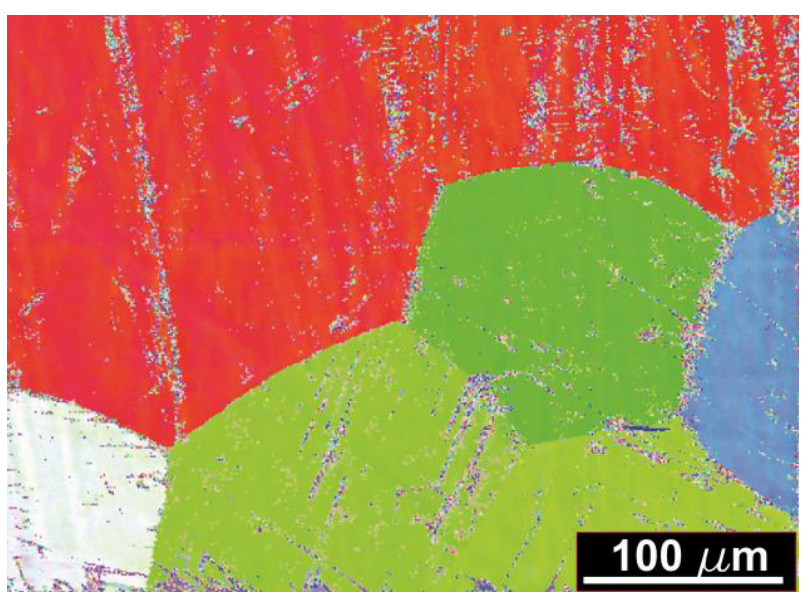

Figure 2. SEM-EBSD picture of sample T20 after a pseudoelastic mechanical test. Prior to the test, the sample was thermally cycled 3 times in the electrical resistivity equipment. Large grains correspond to the austenite phase. Traces of martensite with a gray color can be seen attached to grain boundaries and inside the grains.

Considering the similar resistive behavior of the cycled T20 and T3h samples, it is interesting to compare their mechanical and pseudoelastic behaviors. As it was mentioned in Section 1, the pseudoelastic reversibility depends on the grain size to sample size ratio $(d / D)$. For this reason, special attention was paid to test samples with comparable ratios. Fig. 2 shows the EBSD image of the cycled T20 sample (after the mechanical test) showing a grain size $d$ around $200 \mu \mathrm{m}$. The specimen was $1 \mathrm{~mm}$ thick and $1.5 \mathrm{~mm}$ wide, so its ratio $d / D<<1$. The mechanical testing results are presented in Fig. 3. Due to the low $d / D$ ratio for these samples, the pseudoelastic reversibility in these samples is affected by the interaction between martensite and grain boundaries for deformations higher than $0.5 \%[1,10]$. 


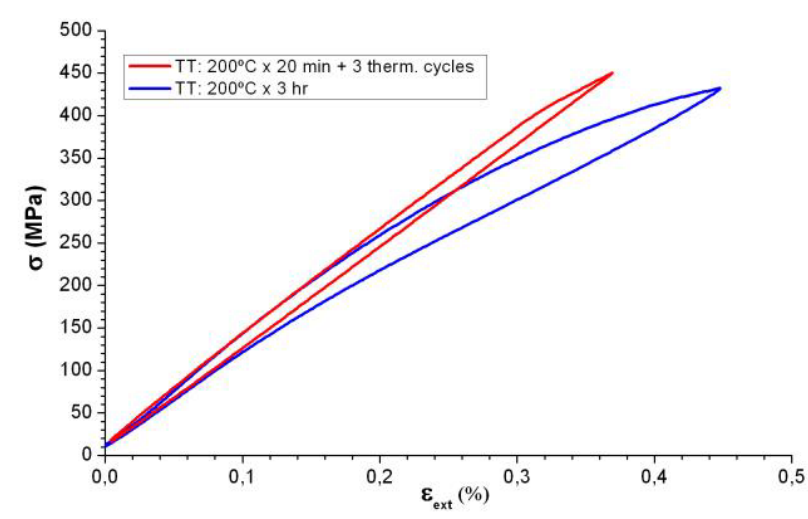

Figure 3. Results of tensile tests at $20^{\circ} \mathrm{C}$ for the cycled $\mathrm{T} 20$ sample (red) and T3h sample (blue).

The curve corresponding to the T3h sample shows a hysteresis loop and complete pseudoelastic recovery up to $0.5 \%$ deformation. The thermally cycled T20 material displays a smaller loop in comparison to $\mathrm{T} 3 \mathrm{~h}$ and it pseudoelastically recovers $0.35 \%$ deformation. When higher deformations were applied, the degree of reversibility decreased and the presence of irreversible deformation was observed at the end of the mechanical cycles. The irreversible deformation is probably related to the presence of $\gamma^{\prime}$ martensite attached to the grain boundaries, as it can be observed in Fig. 2. The EBSD automatic analysis system identified the fcc structure in the observed plates, compatible with the stress induced martensite of this alloy. This is a relevant result because it indicates that a short thermal treatment followed by 3 thermal cycles not only suppressed the thermally induced martensitic transformation but also allowed to obtain some degree of pseudoelastic reversibility. Then, the question arises about the possible microstructural differences caused by the different thermal treatments.

In order to answer that question, systematic TEM observations were performed in samples subjected to different thermal treatments. Figs. $4 a-4 c$ present dark field TEM images acquired, in each case, with the spot identified by an arrow in the corresponding selected area diffraction (SAD) pattern. In all cases, B2 precipitates are illuminated.

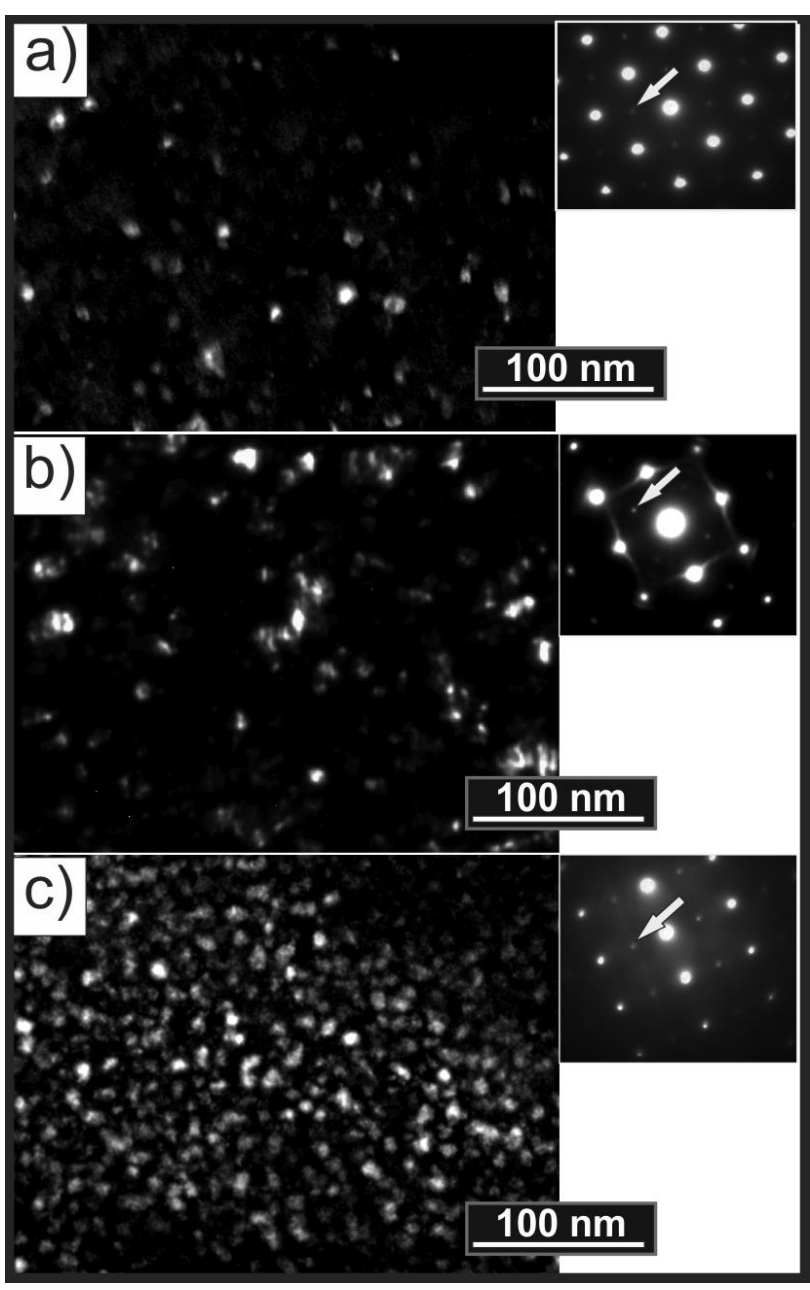

Figure 4. Dark field TEM images of different samples. a) AC sample (Zone axis: [200] $)$. b) T10 sample (Zone axis: [200 $]_{\alpha}$ ). c) T3h sample (Zone axis: [220 $]_{\alpha}$ ). In each case, an arrow points to the diffraction spot used to produce the main image.

The first remarkable finding is that $\mathrm{B} 2$ precipitates are present even in the As-cast condition (Fig. 4a) which would indicate that these precipitates are formed during quenching from $1200^{\circ} \mathrm{C}$. In order to clarify this point, samples of different sizes were quenched from high temperature under different conditions (for example, by direct submersion in water after being retired from the furnace or by quenching embedded in a larger piece of metal). In all cases, precipitates similar to those shown in Fig. 4a were found. Although precipitates are already present in the As-cast condition, there is an evolution as the $200^{\circ} \mathrm{C}$ thermal treatment proceeds. After $10 \mathrm{~min}$ (Fig. $4 \mathrm{~b}$ ) and $20 \mathrm{~min}$ the size and distribution of the precipitates is not very different to what was observed for the AC sample. However, after $3 \mathrm{~h}$ treatment (Fig. 4c) the density of precipitates is considerably increased. Fig. 5 shows a comparison between the measured precipitate size distributions for samples $\mathrm{AC}$ and $\mathrm{T} 3 \mathrm{~h}$. The main precipitate size increases with increasing the thermal treatment time as it goes from $7.7 \mathrm{~nm}$ in the $\mathrm{AC}$ condition to $12.1 \mathrm{~nm}$ in the $\mathrm{T} 3 \mathrm{~h}$ sample. 


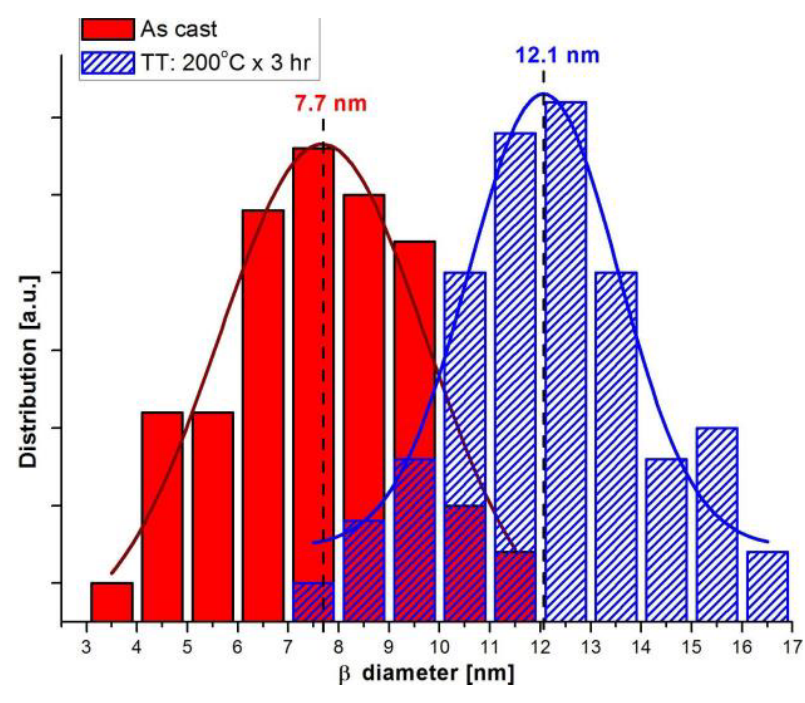

Figure 5. Precipitate size distribution for samples AC (red) and T3h (blue).

Fig. 6 is a TEM bright field image of the interface between the austenite $\alpha$ phase (A) and the martensite $\gamma^{\prime}$ phase (M) for the AC sample. Precipitates are present at both sides of the interface and appear to be coherent with both phases. Elastic distortion contrast is seen around precipitates in the martensite. In addition, there is no clear interface line being the limit between these two phases irregular.

Considering these observed changes in the microstructure and the electrical resistivity results (Fig. 1) it can be concluded that there is a diffusive process and an evolution of $\mathrm{B} 2$ precipitates during the $200^{\circ} \mathrm{C}$ thermal treatment. This evolution could have various different effects on the relative phase stability and the pseudoelastic behavior of this alloy. Some possibilities will now be discussed.

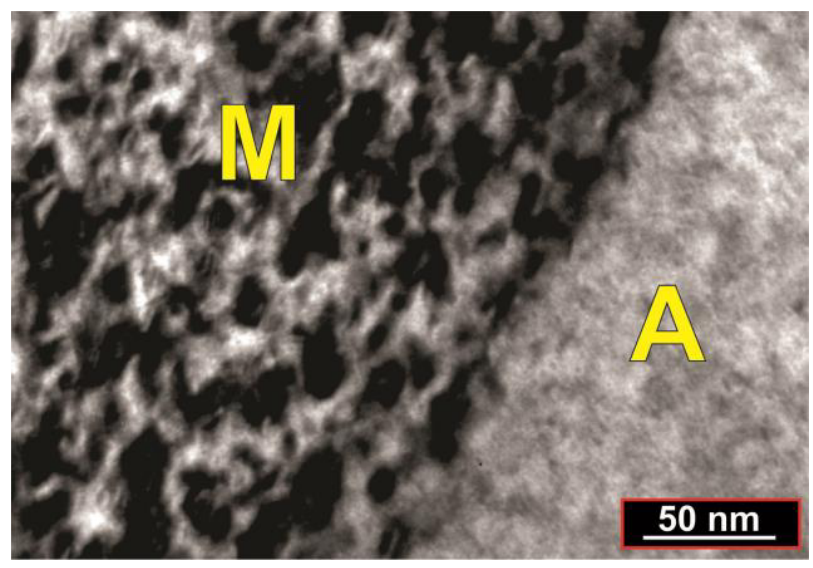

Figure 6. Bright field TEM image of the interface between austenite (A) and martensite (M). Elastic distortion contrast is seen around precipitates in the martensite phase.

\section{Discussion}

The presence of $\mathrm{B} 2$ precipitates is a necessary condition for the development of the pseudoelastic effect in Fe-MnAl-Ni alloys $[16,17]$. They play, at least, two main roles. In first place, the presence of nanometric coherent precipitates have a hardening effect on both the matrix and the martensite, thus reducing the possibility of producing irreversible plastic deformation when load is applied on the material. This effect is aided by the relatively low volume change associated to the $\alpha \leftrightarrow \gamma^{\prime}$ martensitic transformation [2]. In this sense, a larger density of precipitates would be beneficial for the transformation's reversibility.

In second place, Omori et al. showed that precipitates are coherent with both the austenite and the martensite and that they are elastically distorted as a result of the transformation [16]. In line with those results, Fig. 6 shows that coherent precipitates surrounded by elastic distortion contrast are present even in the As-cast condition. The elastic contrast area (with a mean size of about $20 \mathrm{~nm}$ ) around precipitates is only present in the martensite phase. Precipitates in the austenite are coherent and stress-free. In addition, the $\alpha / \gamma^{\prime}$ interface does not appear defined by a given habit plane but is also affected by the elastic distortion around precipitates. Summarizing these findings, both the precipitates and the martensite are elastically affected after the transformation. The associated elastic energy accumulates as the transformation proceeds. When the transformation is produced by thermal changes, the elastic energy accumulation implies that additional undercooling would be necessary to further transform the material. If the size and density of precipitates increases, the elastic barrier to the transformation would increase, hence pushing the $\mathrm{M}_{\mathrm{s}}$ to lower temperatures. Then, as the $\mathrm{M}_{\mathrm{s}}$ decreases also does the amount of transformed material and the associated hysteresis, as seen in the results presented in Fig. 1. Another important effect of the accumulated elastic energy would be that it acts in favor of the reverse transformation $\left(\gamma^{\prime} \rightarrow \alpha\right)$, being this backward stress one of the sources of thermoelasticity for this martensitic transformation. Evidence of this effect can also be found in the mechanical behavior of samples T20 and T3h presented in Fig. 3. Although both samples display some degree of pseudoelasticity, sample T3h shows a better response achieving higher reversible deformations than T20. The difference is probably associated to the higher density of precipitates present in sample T3h that would be more effective in preventing plastic slip and would help to provide a larger backward recovery stress.

Another aspect of the electrical resistivity measurements are the variations related to thermal cycling. As it was mentioned in Section 3, as cycling proceeds the amount of transformed material decreases for samples AC, T10 and T20. This evolution indicates that some irreversible phenomena occur during thermal cycling, where each transformation affects the following one. Considering the body of observations, the irreversibility could be associated to two main phenomena: plastic deformation associated to the transformation and the evolution of precipitates at the higher temperature end of thermal cycles. A large pseudoelastic effect manifests in this material when precipitates meet certain size and distribution conditions that, among other effects, prevent plastic slip. It would then be possible that when such conditions are far from 
the optimum, the formation of permanent defects could take place during thermally induced transformations [18]. These defects would hamper subsequent transformations by interfering with the movement of interfaces. From another point of view, thermal cycling involves taking the samples up to $170^{\circ} \mathrm{C}$. There, a similar, although slower, diffusive process as the one occurring at $200^{\circ} \mathrm{C}$ could take place resulting in a decrease of the $\mathrm{M}_{\mathrm{s}}$ temperature and of the amount of transformed material at the lower temperature end of the cycle. Additional research is being performed in order to clarify this point.

\section{Conclusions}

$\mathrm{Fe}_{43.5} \mathrm{Mn}_{34} \mathrm{Al}_{15} \mathrm{Ni}_{7.5}$ samples subjected to thermal treatments at $200^{\circ} \mathrm{C}$ for different intervals were studied by means of electrical resistivity, mechanical testing, EBSD and transmission electron microscopy.

B2 precipitates were observed in all cases, even in the As-cast condition. The size and density of precipitates increase as the thermal treatment time increases. This evolution is reflected on a reduction of the $M_{s}$ temperature, a decrease in the amount of thermally transformed material and an improvement of the pseudoelastic response. These effects can be associated to the accumulation of elastic strain inside and around coherent precipitates in the martensite phase. An additional hardening effect of the precipitates on both the austenite and the martensite is also beneficial for achieving a large complete pseudoelastic behavior.

\section{Acknowledgments}

The authors gratefully acknowledge the support of ANPCyT (PICT-2012-0884), CONICET (PIP 112201001-00056) and U.N. Cuyo (06/C463). We also thank E. Aburto for helping with quartz encapsulation of samples.

\section{References}

1. T. Omori, K. Ando, M. Okano, X. Xu, Y. Tanaka, I. Ohnuma, R. Kainuma, K. Ishida, Science 333, 68-71 (2011)

2. K. Ando, T. Omori, I. Ohnuma, R. Kainuma, K. Ishida, Appl. Phys. Lett 95, 212504 (2009)

3. R. Umino, X.J. Liu, Y. Sutou, C.P. Wang, I. Ohnuma, R. Kainuma, K. Ishida, J. Ph. Eq. Diffus. 27, 54-62 (2006)

4. J. Mino, V. Komanicky, M. Durisin, K. Saksl, J. Kovac, R. Varga, IEEE Trans. Magn. 51, 4000903 (2015) 5. Y. Sutou, T. Omori, R. Kainuma, N. Ono, K. Ishida, Metall. Mat. Trans. A 33, 2817-2824 (2002)

6. Y. Sutou, T. Omori, K. Yamauchi, N. Ono, R. Kainuma, K. Ishida, Acta Mat. 53, 4121-4133 (2005)

7. Y. Sutou, T. Omori, R. Kainuma, K. Ishida, Mat. Sc. and Tech. 24, 896 (2008)

8. Y. Sutou, T. Omori, R. Kainuma, K. Ishida, Acta Mat. 61, 3842-3850 (2013)

9. Y. Chen, C.A. Schuh, Acta Mat. 59, 537-553 (2011)

10. T. Omori, M. Okano, R. Kainuma, APL Mat. 1, 032103 (2013)

11. T. Waitz, T. Antretter, F.D. Fischer, N.K. Simha, H.P. Karnthaler, Jour. Mech. Phys. Sol. 55, 419-444 (2007)

12. P. La Roca, L.M. Isola, C.E. Sobrero, Ph. Vermaut, J. Malarría, Mat. Today: Proceedings ICOMAT-2014 (in press)

13. P. La Roca, L.M. Isola, Ph. Vermaut, J. Malarría, Appl. Phys. Lett. 106, 221903 (2015)

14. A. Baruj, T. Kikuchi, S. Kajiwara, N. Shinya. Mat. Trans. 43, 585-588 (2002)

15. Y. Tanaka, Y. Himuro, R. Kainuma, Y. Sutou, T. Omori, K. Ishida, Science 327, 1488-1490 (2010).

16. T. Omori, M. Nagasako, M. Okano, K. Endo, R. Kainuma, App. Phys. Lett. 101, 231907 (2012)

17. L.W. Tseng, Ji. Ma, S.J. Wang, I. Karaman, M. Kaya, Z.P. Luo, Y.I. Chumlyakov. Acta Mat. 89, 374 383 (2015)

18. A. Baruj, H.E. Troiani, M. Sade, A. Fernández Guillermet, Phil. Mag. A 80, 2537-2548 (2000) 